\title{
10. DIREITOS REPRODUTIVOS: DA INFERTILIDADE À CASA DE ORATES EM O ALIENISTA
}

\author{
Fabiane Simioni $^{1}$
}

Resumo: Procura-se desenvolver nesse espaço uma análise dos direitos reprodutivos, a partir da análise da personagem D. Evarista, esposa do médico Simão Bacamarte. Machado de Assis, em O Alienista, reproduz o caldo cultural que normatiza e define os valores e as posições de homens e mulheres na sociedade moderna brasileira. Nesse sentido, coerente é a construção de uma personagem feminina que se apresenta, inicialmente, eleita porque reunia as aptidões fisiológicas para o cumprimento de seu principal papel social, o materno. Da mesma forma, a conseqüência lógica para a não realização de tal destino seria, na narrativa machadiana, a loucura.

Palavras-chaves: direitos reprodutivos, infertilidade, loucura.

\begin{abstract}
It seeks to develop an analysis of reproductive rights, from the character D. Evarista, wife of the doctor Simon Bacamarte. Machado de Assis, in O Alienista, reproduces the cultural melting pot that regulates and defines the values and positions of men and women in modern brazilian society. Accordingly, consistent is the construction of a female character who presents initially chosen because it met the physiological ability to fulfill their primary social role, the breast. Likewise, the logical consequence for not conducting such a fate would be madness, in the literary work of Machado de Assis.
\end{abstract}

Keywords: reproductive rights, infertility, madness.

\section{Primeiras considerações}

O Alienista, de Machado de Assis, se presta a uma diversidade de temas e análises: os limites da razão e da loucura; o interesse público e a manipulação política de tal interesse; o mito da neutralidade científica e sua relação com a metodologia científica. Enfim, cada leitor e leitora poderá estabelecer diferentes possibilidades de conexões interpretativas.

\footnotetext{
${ }^{1}$ Doutoranda em Direito (UFRGS/CAPES), professora no CESUCA. 
A partir de um referencial específico, o campo dos direitos reprodutivos ${ }^{2}$, procura-se desenvolver nesse espaço uma outra possível conexão: D. Evarista, esposa do médico Simão Bacamarte, mesmo reunindo condições fisiológicas e anatômicas de primeira ordem, promoveu a total extinção da dinastia dos Bacamartes: não gerou filhos ou filhas.

A jovem D. Evarista, nem bonita nem simpática, estaria apta a dar filhos/filhas robustos, sadios e inteligentes ao novo Sócrates. Nenhum espanto, portanto, com o reducionismo promovido pelo narrador, uma vez que era esse o papel social (único e fundante) destinado às mulheres, nas piores e melhores obras desse gênero literário.

Machado de Assis reproduz o caldo cultural que normatiza e define os valores e as posições de homens e mulheres na sociedade moderna brasileira. Nesse sentido, coerente é a construção de uma personagem feminina que se apresenta, inicialmente, eleita porque reunia as aptidões fisiológicas para o cumprimento de seu principal papel social, o materno. Da mesma forma, a conseqüência lógica para a não realização de tal destino seria, na narrativa machadiana, a loucura.

Se a idéia de saúde, contemporaneamente, está associada ao bem-estar físico, psíquico e social, a infertilidade atribuída exclusivamente a D. Evarista lhe impõe uma condição de enfermidade e, na seqüência autoriza sua internação na Casa Verde, uma espécie de laboratório de loucos de todo espécie, administrado pelo melhor dos médicos de Brasil, Portugal e Espanha, seu marido.

Trata-se de uma narrativa ficcional que naturaliza as diferenças biológicas entre homens e mulheres, com o fim específico de fundamentar uma hierarquia de valores e de sujeitos e eleger um modelo (homem, branco, heterossexual, de classe média/alta), a partir do qual todos devem se subsumir. Em torno de um modelo (de família, de sujeitos, de comportamentos etc.) constrói-se todo um universo de diferenças desvalorizadas, de subcidadãos e subcidadãs.

\footnotetext{
${ }^{2}$ Os direitos reprodutivos, assim como os direitos sexuais, de acordo com Piovesan (1998: 168), são um conjunto de direitos básicos relacionados com o livre exercício da sexualidade e da reprodução humana, circulando no universo dos direitos civis e políticos (quando se referem à liberdade, autonomia, integridade etc.) e aos direitos econômicos sociais e culturais (quando se referem às políticas do Estado). Para a mesma autora, os direitos reprodutivos exigem um duplo papel do Estado: eliminar a discriminação contra a mulher na área da saúde (paradigma repressivo/punitivo) e assegurar o acesso a serviços de saúde, incluindo o planejamento familiar (paradigma promocional) (PIOVESAN, 2002: 71).
} 
Simão Bacamarte, o varão ilustre, de alto espírito e submetido somente aos mestres e à Deus tinha na feliz esposa, D. Evarista, um anjo, a caridade, a vida e a consolação. Embora, também ela tenha sido recolhida à Casa de Orates.

\section{Moralidades e infertilidade}

Diante desse cenário, perguntamos se somente na ficção as mulheres que não tem filhos ou filhas são percebidas como loucas?

Nas classes populares, por exemplo, o constrangimento a que se vêem submetidos mulheres e homens pela ausência de filhos ou filhas enseja um comprometimento de ordem moral que atinge as identidades masculina e feminina. 'Pertubação' e 'vergonha' são categorias explicativas dos efeitos e das conseqüências da ausência de filhos/filhas nas trajetórias individuais dessas pessoas.

No fragmento de uma entrevista realizada por Vargas (2002: 326-8), a entrevistada fala de sua 'vergonha' em não ter filhos ou filhas:

“E vou ser até sincera. Às vezes, eu fico até com vergonha. Porque, às vezes, eu fico pensando assim: 'será que - um exemplo, uma suposição - a pessoa...' como minha cunhada. Teve três filhos, tem até um bebê agora com três meses. Aí, ela deixa muito o bebê comigo. Eu fico pensando: 'será que se eu falar o meu problema, ela vai duvidar?'Vai ficar depois, assim, qualquer coisa vai querer jogar na minha cara que eu não tenho filho e que eu sou uma pessoa até, assim, recalcada?".

O 'problema' da ausência de filhos/filhas aparece na maioria das histórias das mulheres entrevistadas por Vargas (2002: 329-330):

\footnotetext{
"Mesmo sabendo que pelo menos não é assim, não é coisa que ela arrumou, que é coisa que aconteceu. Ela já nasceu com esse problema. Mas ela se sente diferente. Ainda mais quando ela vê uma mulher ou grávida ou o neném novinho. [...] A mulher que não tem filho, tem muita gente que fala assim: 'uma figueira', né, que não tem fruto".
} 
Segundo Vargas (2002: 311), a ausência de descendência não necessariamente está ligada a doença, mas passou a ser tratada historicamente como uma patologia médica. Sob a perspectiva de uma patologia, houve a necessária correspondência entre tratamento e intervenção médica e infertilidade, eis que esta está intimamente ligada ao corpo humano, mais precisamente ao corpo feminino.

Pode-se, ainda, pensar a infertilidade no contexto das experiências humanas universais de sofrimento, aflição, perturbação, mal-estar, concebida como doença física na tradição cultural ocidental e, portanto, tratável pelo sistema de saúde. (VARGAS: 2002: 342).

De outra forma, a Organização Mundial da Saúde define a infertilidade como a ausência de concepção natural depois de, pelo menos, um ano de intercurso sexual periódico sem proteção anticoncepcional. A infertilidade pode ser relacionada a diversas causas. Segundo Corrêa (1997: 178), o perfil de prevalência da infertilidade feminina está associado, em nosso país, a um perfil médico-sanitarista deficiente: “[...] ainda que de magnitude desconhecida, o problema da infertilidade poderia ser minorado pelo combate às causas preveníveis (fibroses e bloqueio de trompas) através de um bom sistema de saúde pública".

A infertilidade tem uma configuração difícil, com diagnósticos médicos e critérios pouco precisos enquanto categoria. Existe um grande número de situações de infertilidade nas quais não há obstáculo fisiológico irreversível para a ocorrência de uma gravidez, mesmo assim ela não ocorre.

O fato de a infertilidade, então, estar intimamente conectada ao corpo feminino opera diferenças no modo pelo qual homens e mulheres recorrem aos serviços de saúde. Destaca-se, ainda, para além das diferenças de gênero no que diz respeito à infertilidade há uma considerável diferença de classe social quanto à acessibilidade aos serviços de saúde para o fato da ausência de filhos/filhas. Existem poucos serviços públicos, os quais possuem critérios rigorosos de seleção dos possíveis pacientes/usuários. Em virtude da grande demanda e da diminuta oferta de vagas, muitas vezes há uma fila de espera de mais de um ano para o atendimento.

Além da desproporção entre a demanda e a oferta no setor público, ocorre que o Sistema Único de Saúde não cobre os medicamentos utilizados nas diferentes fases do 
'tratamento' médico. Dessa forma, para as classes sociais mais abastadas a oferta e as possibilidades de escolhas são maiores.

Essa forma diferenciada de busca por auxílio médico reflete a existência de uma lógica específica presente na configuração simbólica da demanda por filhos/filhas. Tal demanda revela, portanto, características distintivas das identidades, bem como expõe publicamente características físico-morais de mulheres e homens.

O fato biológico irrefutável é que em todas as sociedades humanas há uma preocupação comum relativa a procriação. A partir dessa exigência, são modulados, construídos e redefinidos os mecanismos de legitimidade de pertencimento ao grupo, os parâmetros para a constituição da identidade de uma pessoa, a regulamentação de direitos e deveres individuais. Cada sociedade segue um costume coerente que the é próprio e é socialmente compartilhado (HÉRITIER: 2000: 98).

Conforme Rotânia (2001: 43), desde a Antiguidade a procriação é um território onde transitam ponderações sobre comportamentos considerados adequados ou não e sobre as devidas recomendações em relação aos cuidados que deveriam ser tomados nas relações heterossexuais que teriam por objetivo a consecução dos fins precípuos de um intercurso sexual. Contemporaneamente, foram substituídas as palavras dos sábios ou dos pajés pelas dos clínicos e especialistas médicos diante da não concretização da demanda por filhos/filhas. Isto porque, como no início da organização moderna das sociedades ocidentais, se acredita que pela forma como se realizam as uniões sexuais é possível determinar as características do embrião e marcar seu desenvolvimento.

Esta simbologia ainda está muito presente entre nós. O projeto de ser humano advindo da união sexual ou da terapia médica está fadado a carregar os estigmas/símbolos anteriores à sua própria existência. Tal responsabilidade pode ser medida pelos cuidados na seleção, organização e normatização daqueles que terão acesso, por exemplo, às tecnologias de reprodução medicamente assistidas.

O equilíbrio observado em sua plenitude na natureza deve ser preservado naquilo que o ser humano maneja, a fim de que seja compatível com a perfectibilidade encontrada na ordem do natural. Por isso, todo o esforço prescritivo em um modelo tradicional de constituição familiar, a fim de evitar possíveis descaminhos. 
As tentativas de reprodução artificial, mutação e/ou manipulação genéticas não são propriamente 'novas'. No campo da reprodução humana, as experiências de Inseminação Artificial iniciam no século XVIII. Em 1791, o médico inglês Hunter realizou a experiência de injetar esperma de um homem na vagina de sua esposa. Entretanto, somente em 1799 foi relatada a primeira gravidez resultante do procedimento.

De acordo com Rohden (2000), no Brasil, a fecundação artificial já era descrita pelo periódico Brazil Medico, em 1912, da seguinte forma: “A técnica de fecundação artificial é simples. Estando tudo preparado, faz-se com que o coito se realize com um condom (camisa de Vênus), onde o esperma se ajunta, recolhe-se-o depois em uma cápsula esterilizada, e com uma seringa de Braun injeta-se um pouco dele no útero".

Na primeira metade do século $X X$, os estudos sobre as células e o desenvolvimento da genética contribuem para a complexificação e especificação dos processos reprodutivos e genéticos.

Em 1953, nos Estados Unidos, é realizada a primeira fecundação por inseminação artificial com esperma congelado. Com a possibilidade de congelamento de células germinativas, desenvolvem-se instituições específicas para o cuidado desse tipo de material genético, como os bancos de sêmen, e, hoje, os bancos de óvulos e de embriões ${ }^{3}$.

A fertilização in vitro (FIV) e a transferência de embriões em animais começam a ser desenvolvidas nos anos cinqüenta, dando origem à FIVETE ${ }^{4}$ - técnica básica dos 'bebês de proveta'. As tentativas tornadas públicas de utilização dessa técnica em humanos data do início da década de setenta. Em 1978, na Inglaterra, é realizada a primeira fecundação in vitro levada a termo com o nascimento de Louise Brown - o primeiro 'bebê de proveta' do mundo.

\footnotetext{
${ }^{3}$ Na França, existem bancos de sêmen desde 1973 (Centre d’Étude et de Conservation du Sperme - CECOS). No Brasil, o primeiro banco de sêmen foi instalado no Hospital Albert Einstein, em 1993. Nos referidos bancos de armazenamento, os gametas são congelados e os pré-embriões são criopreservados até que concretizem seus fins ou no caso de embriões excedentes, sejam doados, utilizados em pesquisa ou eliminados. Até maio deste ano, não havia uma normatização a respeito do destino desses embriões. Cada clínica operava segundo seus próprios critérios organizacionais. A partir da publicação no Diário Oficial da União da Resolução 2.013/2013, do Conselho Federal de Medicina, a destinação dos embriões e gametas deve seguir manifestação expressa dos usuários. A resolução determina ainda que os embriões criopreservados com mais de 5 (cinco) anos poderão ser descartados se esta for a vontade dos pacientes, e não apenas para pesquisas de células-tronco, conforme previsto na Lei de Biossegurança.

${ }^{4}$ Em inglês, in vitro fertilization embrio-transfert (FIV-ET).
} 
De acordo com Rohden (2000: 238), nas primeiras décadas do século XX, o assunto ganha espaço em razão da queda das taxas de natalidade e dos resultados deste fenômeno para as nações. De outra forma, no cenário médico brasileiro alguns estudos passam a tratar da ausência de fecundidade e suas conseqüências para, primeiramente os indivíduos e para o casal, posteriormente, para a sociedade.

Apesar da preocupação com a referida queda das taxas de crescimento populacional, observa-se no Brasil o argumento da solidariedade para com o contingente cada vez maior de crianças abandonadas e/ou órfãos para limitar ou, em algumas hipóteses mais extremas, impedir o acesso às tecnologias reprodutivas. Partindo de outra lógica, também a defesa da autonomia não é bem aceita na sociedade brasileira. Logo, estes argumentos não servem para fundamentar um possível direito ao acesso às tecnologias reprodutivas, pois esse 'direito de gerar' através do uso dessa tecnologia implicaria a alteração da sacralidade da maternidade e a exigência da presença de um pai, seja o biológico ou o social.

\section{Normatização da (in)fertilidade}

O acesso das pessoas às práticas médicas de reprodução assistida tem gerado intenso debate nos mais diferentes campos: na medicina, no direito, na mídia, etc.

Entre as principais questões discutidas, para Simioni (2010), está a possibilidade de acesso para pessoas ou casais homossexuais. Isso porque, tal prática desestabilizaria uma 'relativa' segurança que existe quando os indivíduos associam as uniões heterossexuais à continuidade da espécie humana. Dessa forma, na hipótese de não alinhamento dos estilos de vida com um determinado modelo hegemônico de família, há a necessidade de se combatê-lo, na tentativa de manutenção das relações de parentesco e filiação circunscrita aos critérios de conjugalidade e heterossexualidade.

Do ponto de vista normativo, recentemente o Conselho Federal de Medicina publicou a Resolução no. 2.013/2013 para orientar as normas éticas para a utilização das 
técnicas de reprodução assistida. Trata-se do único ato em vigor que se propõe a regulamentar tais procedimentos médicos ${ }^{5}$.

Esta resolução tem como critério de acessibilidade a indicação terapêutica do uso das técnicas de reprodução medicamente assistida. De outra parte, a Resolução afirma que toda pessoa capaz, solteira ou não, de qualquer orientação sexual, pode ser receptoras das técnicas de reprodução assistida ${ }^{6}$.

A condição de D. Evarista, de ausência involuntária de descendência, enseja sentimentos de culpa e vergonha pela incapacidade de gerar, além da prevalência de um mal-estar gerado pela sensação de incompletude. Embora tais sentimentos não tenham sido explorados pela narrativa machadiana, propomos o exercício imaginativo de ampliar as possibilidades analíticas.

Outra das entrevistadas por Vargas (2002: 336) vincula o 'não poder engravidar' ao 'não ser mulher', constituindo-se, assim, em uma das medidas da própria identidade que se vê ameaçada:

\begin{abstract}
"Só porque a gente não pode ter filho a gente não é mulher? Ela se sente mais mulher porque pode engravidar, ter filho [...] Eu já ouvi também falando de mim que mulher que não pode ter filho não é ... [...] Falaram que eu não era mais mulher. Porque eu não posso ter filho, eu não sou mulher".
\end{abstract}

Pergunta-se até que ponto a reprodução, como um imperativo humano, poderia ser reflexo de um dever/obrigação, e não de um direito subjetivo.

Nesse sentido, Corrêa (2001: 189) afirma que, em alguns modelos societais, o indivíduo tem o dever de assegurar sua continuidade pela descendência. No Ocidente, ele procria também por esses motivos, mas principalmente porque 'deseja ter filhos/filhas'. Mesmo que persista uma forte pressão social a favor da realização desse desejo, a procriação, em nossa sociedade, não é tida como um dever social inquestionável. E nos casos de impossibilidade de realização, esse desejo era 'resolvido' pela adoção.

\footnotetext{
${ }^{5}$ Sobre o debate no Poder Legislativo quanto à regulamentação das técnicas de reprodução assistida ver: SIMIONI, Fabiane. Tecnologias Reprodutivas: razão pública e normatização. In: HEILBORN, M.; AQUINO, E. et. all. (orgs). Sexualidade, Reprodução e Saúde. Rio de Janeiro: Editora FGV, 2009, p. 205-233.

${ }^{6} \mathrm{Na}$ própria justificativa da resolução, há referência expressa a decisão do Supremo Tribunal Federal que reconheceu e qualificou como entidade familiar a união estável formada por pessoas do mesmo sexo (ADI 4.277 e ADPF 132).
} 
Dessa forma se justifica que aqueles que não cumprem esse dever de continuidade da espécie devam procurar 'remediar' tal obrigação, seja pela adoção, seja pelo recurso às tecnologias reprodutivas.

De fato, a preocupação em resolver socialmente a ausência involuntária de filhos/filhas implicou, em quase todas as sociedades, arranjos mais ou menos públicos entre os indivíduos dos dois sexos, indicando que a esterilidade foi sempre mal vista e repudiada como uma infelicidade. Todavia, em quase todas as sociedades humanas, a falta de filhos/filhas é, antes de tudo, uma responsabilidade das mulheres. Em muitas sociedades, uma mulher só é considerada e designada como tal depois de ter procriado. Na China, mulheres que não têm filhos/filhas são apontadas como "demônios de uma natureza tão perigosa, que mesmo os outros demônios se afastam de seu caminho" (HÉRITIER, 2000: 104).

Segundo Héritier, o conjunto de questões com as quais nos defrontamos no campo da assistência médica à reprodução humana, cujas soluções imaginamos que se tornem possíveis de uma forma radicalmente nova, pelos avanços científicos e tecnológicos, tem encontrado soluções não técnicas, ancoradas na estrutura social e no imaginário coletivo dos grupos que as têm adotado.

Essas soluções não técnicas estão apoiadas, sobretudo, na palavra (ordem da cultura). É pela palavra, pelo discurso que se preenche e significa a forma pela qual as aproximações e distanciamentos entre a ordem da cultura e da natureza (neste caso referido, pelos laços sangüíneos) devem ser compartilhados pelos indivíduos.

Assim, as práticas de reprodução medicamente assistida nada mais são do que mecanismos - aperfeiçoados pelo desenvolvimento científico e tecnológico - já manejados, em alguma medida, por diferentes sociedades através de suas estruturas e instituições sociais. Encontramos na sociedade contemporânea as mesmas práticas de manutenção e preservação da espécie diante das impossibilidades fisiológicas, entretanto elas estão sob diferentes registros ${ }^{7}$.

\footnotetext{
${ }^{7}$ Para exemplificar, Héritier (2000: 107) destaca dois relatos de práticas observadas entre os Samo de Burkina Fasso. O primeiro trata de uma das formas de casamento em que uma menina é prometida desde o seu nascimento ou infância. Entretanto, antes de ser entregue ao seu marido, a jovem mantém durante três anos, no máximo, relações com um amante de sua escolha, e isto é inteiramente oficial, uma vez que o amante a 
De acordo com Héritier, todas as fórmulas que nós pensamos serem novas são possíveis socialmente e já foram experimentadas em sociedades particulares. Mas, para que elas funcionem como instituições, é preciso que elas sejam mantidas sem ambigüidades pela lei do grupo, inscritas firmemente na estrutura social e que correspondam ao imaginário coletivo das representações de pessoa e identidade.

O social não é jamais redutível ao biológico, nem, a fortiori, ao genético. Não é também definível como uma simples associação de direitos individuais. Encontramo-nos num campo de disputas onde cada um apela, em função de seus interesses, ora ao biológico ora ao social.

\section{Considerações finais}

Estudos realizados nas últimas décadas atestam inequivocamente o processo de transformações socioculturais porque passaram homens e mulheres. Tais mudanças tornamse cada vez mais decisivas para a transformação dos papeis sociais. A maior participação das mulheres no mercado de trabalho, os movimentos feministas, o incremento dos métodos anticoncepcionais, possibilitando à mulher um controle do próprio corpo e da sexualidade, iniciaram um processo de mudança na sociedade, sobretudo, nas camadas mais abastadas e escolarizadas da população.

Entretanto, a experiência cotidiana e a literatura em geral nos informam que as mudanças não foram suficientes para modificar a rígida divisão de papéis sexuais, tanto no espaço público do mercado - reservado primordialmente aos homens - quanto na esfera privada das relações familiares.

Os diferentes papéis assumidos pela mulher trouxeram uma nova configuração à maternidade, o que, por sua vez, implicou uma nova organização para o exercício da

visita na casa paterna. Os próprios primogênitos nascidos sob tais circunstâncias sabem, segundo uma metáfora usual, que nasceram 'na casa de seu avô'. A jovem se une ao seu marido logo após o nascimento de um filho, que é considerado o primogênito de sua união legítima. No segundo caso, observa-se que, frente à ausência de filhos, a mulher finge concordar em deixar o seu marido legítimo, toma um marido secundário e retorna a seu esposo grávida ou mãe de um ou vários filhos, que serão deste último. Tal prática mascara, portanto, o fato da esterilidade masculina, e podemos, dessa forma, identificá-la como uma inseminação por doador, ainda que sua razão de ser ocorra em um registro simbólico diverso daquele que encontramos em nossa sociedade. Podemos depreender de tal prática que tanto a palavra quanto o sangue estabelecem a filiação, entretanto, estes diferentes mecanismos não se distinguem quanto a inserção de uma filho na linhagem parental. 
paternidade na família do final do século $X X$, início do século $X X I$, uma vez que o padrão antigo não mais respondia às necessidades e possibilidades dessa família.

A maternagem das mulheres no espaço doméstico e a exclusão dos homens dessa esfera são aspectos de uma organização social de gênero sustentada e reproduzida também pelas estruturas de personalidade masculina e feminina. Portanto, a biologia e o instinto por si não explicam a divisão sexual do trabalho. O significado das diferenças individuais entre os sexos não se define biologicamente.

Em nossa sociedade, não se faz necessário explicitar a 'necessidade de mãe' que um filho/filha demanda. E atribui-se às mulheres, por sua vez, a expressão de desejos/instintos naturais quando intentam ter filhos/filhas. Por outro lado, quando uma mulher não se torna mãe, como D. Evarista, sua identidade, sua condição humana e sua saúde mental podem ser questionadas.

\section{REFERÊNCIAS BIBLIOGRÁFICAS}

CORRÊA, Marilena Villela. Novas tecnologias reprodutivas: limites da biologia ou biologia sem limites? Rio de Janeiro: EdUERJ, 2001.

HÉRITIER, Françoise. A coxa de Júpiter - notas sobre as novas tecnologias de reprodução, Revista Estudos Feministas, v. 8, n. 1, 2000, p. 98-114.

PIOVESAN, Flavia. Os direitos reprodutivos como direitos humanos. In: BUGLIONE, S. (org). Reprodução e Sexualidade: uma questão de justiça. Porto Alegre: Sergio Fabres Editor, 2002, p. 61-92.

PIOVESAN, Flavia. Temas Atuais de Direitos Humanos. São Paulo: Limonad, 1998.

ROHDEN, Fabíola. Uma ciência da diferença: sexo, contracepção e natalidade na medicina da mulher. Rio de Janeiro: UFRJ/Programa de Pós-graduação em Antropologia Social, Tese, 2000.

ROTANIA, A. A celebração do temor: biotecnologias, reprodução, ética e feminismo. Rio de Janeiro: E-papers, 2001.

SILVA, Reinaldo Pereira e. Introdução ao biodireito: investigações político-jurídicas sobre o estatuto da concepção humana. São Paulo: LTr, 2002.

SIMIONI, Fabiane. Monoparentalidade e Tecnologias Reprodutivas. In: BUGLIONE, S.; VENTURA, M. (orgs.). Direito à Reprodução e à Sexualidade: uma questão de ética e de justiça. Rio de Janeiro: Ed. Lúmen Júris, 2010, p. 295-319. 
SIMIONI, Fabiane. Tecnologias Reprodutivas: razão pública e normatização. In: HEILBORN, M.; AQUINO, E. et. all. (orgs). Sexualidade, Reprodução e Saúde. Rio de Janeiro: Editora FGV, 2009, p. 205-233.

VARGAS, Eliane Portes. Gênero e infertilidade na ótica feminina. In BARBOSA, Regina et. al. (orgs.). Interfaces Gênero, Sexualidade e Saúde Reprodutiva. Campinas: Editora da UNICAMP, 2002, p. 309-347. 